\title{
СПЕЦИФИКА И ВОЗМОЖНОСТИ УПРАВЛЕНИЯ ВЗРЫВООПАСНЫМИ ОБЪЕКТАМИ
}

\author{
Волков В.Э. ${ }^{1}$ \\ ${ }^{1}$ Одесская национальная академия пищевых технологий, Одесса \\ Email: victor@te.net.ua
}

Copyright (C 2014 by author and the journal "Automation technological and business - processes". This work is licensed under the Creative Commons Attribution International License (CC BY). http://creativecommons.org/licenses/by/4.0/

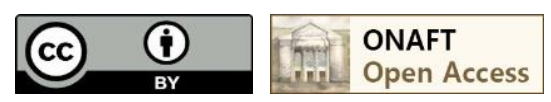

\section{Аннотация}

Произвольный взрывоопасный объект рассмотрен как объект управления. Изучены различные способы и возможности управления взрывоопасными объектами.

\begin{abstract}
Arbitrary explosive object is considered as the object of control. Different ways and possibilities for control of explosive objects are studied.
\end{abstract}

Ключевые слова

Взрывоопасность, взрывоопасный объект, управление, инерционность по каналу управления.

Любой взрывоопасный объект (BOO) может рассматриваться как объект управления (УО) с точки зрения обеспечения его взрывобезопасности. Цель управления состоит в переводе ВОО во взрывобезопасное состояние и поддержание его в этом состоянии. Если эта цель по тем или иным причинам технического или технологического характера в полной мере недостижима, она трансформируется в иную цель, а именно: уменьшение или минимизация риска возникновения взрыва и (как подцель) минимизация возможных последствий взрыва. Минимизация возможных последствий взрыва связана, в свою очередь, с выбором оптимального способа взрывозащиты.

Современные промышленные и транспортные объекты представляют собой столь сложные системы, что управление взрывобезопасностью этих объектов не может быть автоматическим, а допускает только некоторую

степень автоматизации. За человеком остается значительная часть функций управления.

Управляющими параметрами могут быть:

1) физико-химические параметры среды (смеси или вещества), которая может быть взрывоопасной;

2) геометрические параметры, определяющие форму объема, в которую заключена среда и характер поверхности, ограничивающей этот объем (взрыв в неограниченном газовом или парогазовом облаке можно рассматривать как частный случай);

3) инициирующее энерговыделение.

При этом физико-химические параметры среды можно изменять в режиме оперативного управления, тогда как геометрические параметры, определяющие форму и свойства поверхности, ограничивающей среду, нужно задавать на стадии проектирования и возможно изменять, как правило, только при реконструкции объекта. Управление инициирующим энерговыделением, - насколько оно вообще возможно, - связано с жестким соблюдением правил и норм техники безопасности. 


\section{$\underline{1}$ ПИТАННЯ ТЕОРІЇ, МЕТОДИ ТА АЛГОРИТМИ ЕФЕКТИВНОГО АВТОМАТИЧНОГО УПРАВЛІННЯ ОБ'ЄКТАМИ ХІМІКО-ТЕХНОЛОГІЧНОГО ТИПУ}

Если использовать классификацию управления по характеру УО, можно выделить три типа процессов управления:

1) технологическое управление;

2) организационное управление;

3) организационно-технологическое управление.

Практически любой потенциально взрывоопасный объект включает неразрывно связан с человеком или коллективом людей, которых можно считать в определенном смысле составляющей этого объекта. По этой причине управление взрывобезопасностью есть комбинированное, организационно-технологическое управление.

Если технологическое управление осуществляется посредством сигналов, то организационное посредством документов (инструкций, указаний и директив). Организационное управление взрывобезопасностью, в частности, осуществляется в первую очередь посредством инструкций по технике безопасности и охране труда и контролем за соблюдением этих инструкций.

Главная цель организационного управления взрывобезопасностью связана либо с недопущением энерговыделения, близкого к энерговыделению, инициирующему пожар или взрыв или превышающему такое энерговыделение, либо с поддержанием среды в состоянии, выходящем за рамки концентрационных пределов воспламенения. Иными словами, точное соблюдение инструкций по технике безопасности направлено в основном на недопущение возгорания, т.е. на решение проблемы пожаробезопасности, а проблема взрывобезопасности в данном случае решается косвенно, по принципу «не загорится - не взорвется» (в тех случаях, когда неизбежно практически мгновенное перерастание пожара во взрыв, проблемы пожаробезопасности и взрывобезопасности с точки зрения недопущения инициирующего энерговыделения практически эквивалентны). Исключение из этого правила составляют только отдельные виды конденсированных взрывчатых веществ (КВВ), которые по своей природе не способны к «медленному» горению, а только к взрыву (обычно детонационного характера): но для этих КВВ энергия инициирования взрыва достаточно велика и для ее выделения требуется некоторый первичный взрыв (взрыв детонатора), а следовательно подобный взрывной процесс не может быть отнесен к числу случайных взрывов.

Вся практика эксплуатации ВОО свидетельствует о том, что организационное управление взрывобезопасностью само по себе не может гарантировать абсолютную взрывобезопасность объекта. Это связано с рядом факторов.

Во-первых, величина инициирующего взрыв энерговыделения (весьма сильно зависящая от способа энерговыделения), понимаемая как минимальная энергия воспламенения среды, для ряда сред определяется весьма неточно. В полной мере это утверждение относится, например, к пылевоздушным смесям пылей органических продуктов, таких как целлюлоза, древесный уголь, корица, цитрусовая кожура, кукурузный крахмал, сухое молоко, ржаная и пшеничная мука, сахар и т.п., которые весьма часто образуются в процессе различных производств. Примерно с середины 70-ых гг. ХХ-го века и по сей день считается [1-7], что минимальная энергия воспламенения для подобных сред меняется в пределах $20 \div 100$ мДж, однако в рамках круглого стола 7-го Международного симпозиума по опасности, предотвращению и подавлению промышленных взрывов (Seventh International Symposium on Hazards, Prevention and Mitigation of Industrial Explosions: Thirteeenth International Colloquim on Dust Explosions \& Eigth Colloquim on Gas, Vapor, Liquid, and Hybrid Explosions), проходившего в Санкт - Петербурге в период с 7 по 11 июля 2008 г., рядом специалистов была высказана точка зрения, что инициирующее энерговыделение для таких сред меняется в пределах $2 \div 5$ мДж (т.е. на порядок меньше!) [8,9].

Во-вторых, для ряда ситуаций неточно определяются и концентрационные пределы воспламенения (хотя в этом случае расхождения различных теоретических и экспериментальных данных не столь значительны как для инициирующего энерговыделения). Кроме того, весьма затруднительно контролировать поддержание состояния гетерогенной среды вне концентрационных пределов воспламенения не только в рамках некоторого достаточно большого объема в целом, но и равномерно по всему объему (с точки зрения механики сплошных сред - в каждой точке этого объема). И, наконец, в некоторых случаях сама технология производства или хранения требует - в силу тех или иных причин - пребывания среды в концентрационном состоянии, допускающем горение и взрыв.

В-третьих, - это субъективный фактор, - соответствующие инструкции по технике безопасности и охране труда по разным причинам могут нарушаться даже при самом жестком контроле за их соблюдением [10]. К тому же возможно возникновение нештатных производственных ситуаций, которые приводят к нарушению этих инструкций. 


\section{I ПИТАННЯ ТЕОРІЇ, МЕТОДИ ТА АЛГОРИТМИ ЕФЕКТИВНОГО АВТОМАТИЧНОГО} УПРАВЛІННЯ ОБ'ЄКТАМИ ХІМІКО-ТЕХНОЛОГІЧНОГО ТИПУ

Таким образом, управление взрывобезопасностью объекта должно быть не только организационным, но и технологическим. Настоящая работа посвящена именно вопросам технологического и организационнотехнологического управления взрывобезопасностью.

Возможности по предотвращению пожаров и взрывов весьма разнообразны [1-7], но решение этой проблемы остается неоднозначным и сложным.

Очевидно, что:

- все разнообразие многочисленных положений, нормативов и правил соблюдения пожаро- и взрывобезопасности не гарантирует взрывобезопасность предприятий, оборудования, транспортных систем и других объектов. Отчасти это связано с тем, что данные положения и правила не могут охватить все многообразие возникающих ситуаций, отчасти - с тем, что правила не всегда соблюдаются. Последний факт обусловлен как недостаточностью дисциплины соблюдения правил охраны труда и техники безопасности и низкой квалификацией персонала (субъективный фактор), так и сложностью, а в некоторых случаях неточностью или нечеткостью самих правил (объективный фактор);

- желательно максимально снизить негативное влияние субъективных факторов на взрывобезопасность системы, применяя автоматические и автоматизированные средства управления взрывобезопасностью;

- пассивные методы обеспечения пожаро- и взрывобезопасности и ослабления действия взрыва [2,3] (использование полностью безопасного оборудования, применение огнепреградителей и ловушек пламени, аварийный сброс давления взрыва, применение деформируемых конструкций, применение ловушек детонации) требуют грамотного проектирования зданий, предприятий, оборудования и других систем, что требует дополнительных аналитических исследований и соответствующего программного инструментария. Таким инструментарием может быть интеллектуальная система поддержки принятия решений (ИСППР) по взрывобезопасности и взрывозащите. Разумное применение пассивных методов если и не позволяет дать абсолютную гарантию взрывобезопасности, то существенно снижает риск возникновения взрыва, а также минимизирует его разрушительное действие;

- активные методы обеспечения пожаро- и взрывобезопасности и ослабления действия взрыва [2,3] (аварийная остановка процесса, введение ингибитора или флегматизатора, принудительный сброс давления взрыва блокирование места взрыва быстродействующими устройствами) требуют оперативного решения, принимаемого оператором. При этом желательно оснастить оператора ИСППР по взрывобезопасности. Такая ИСППР может быть использована также и для обучения самого оператора;

- для правильного подбора и сочетания весьма многочисленных и разнообразных пассивных и активных методов обеспечения пожаро- и взрывобезопасности, а также для разработки и реализации различных комплексов профилактических мероприятий и соответствующей подготовки персонала также требуется соответствующая ИСППР. ИСППР по взрывобезопасности является, таким образом, важнейшей составной частью комплексной системы управления ВОО с целью поддержания его во взрывобезопасном состоянии.

Выделяя ВОО как УО из среды, необходимо указать его входные и выходные параметры. Входные параметры (входы) определяют воздействие среды на объект. При изменении информации на входах изменяется внутреннее состояние ВОО и, как следствие, изменяются его выходные параметры (выходы).

ВОО, рассматриваемый как УО, весьма специфичен. Эта специфика обусловлена двумя факторами: вопервых, системной сложностью самого объекта, а во-вторых, некоторой противоречивостью в постановке задачи управления (в ряде случаев объект во взрывобезопасном состоянии в принципе не может функционировать, поэтому можно говорить только о повышении уровня взрывобезопасности объекта, но гарантировать его взрывобезопасность невозможно). Специфика сложного - с точки зрения имеющих место физико-химических процессов - ВОО проявляется в определении его входных и выходных параметров, а также в выборе принципа управления объектом.

В простейших случаях, когда пожаро- и взрывобезопасность объекта определяются значениями небольшого числа (одного-двух) слабо связанных между собой параметров, управление объектом легко осуществляется по принципу обратной связи.

Например, при хранении и перевозке в закрытых объемах (грузовых отсеках судов и т.п.) веществ, способных к самовоспламенению (таких, скажем, как аммиачная селитра или нитрат аммония $\mathrm{NH}_{4} \mathrm{NO}_{3}$ ), для предотвращения теплового взрыва достаточно осуществления контроля только за температурой объекта, которая является выходным параметром. Структурная схема управления подобным объектом (потенциально пожароопасным и взрывоопасным) может иметь вид, изображенный на Рис.1. 


\section{1 ПИТАННЯ ТЕОРІЇ, МЕТОДИ ТА АЛГОРИТМИ ЕФЕКТИВНОГО АВТОМАТИЧНОГО} УПРАВЛІННЯ ОБ'ЄКТАМИ ХІМІКО-ТЕХНОЛОГІЧНОГО ТИПУ

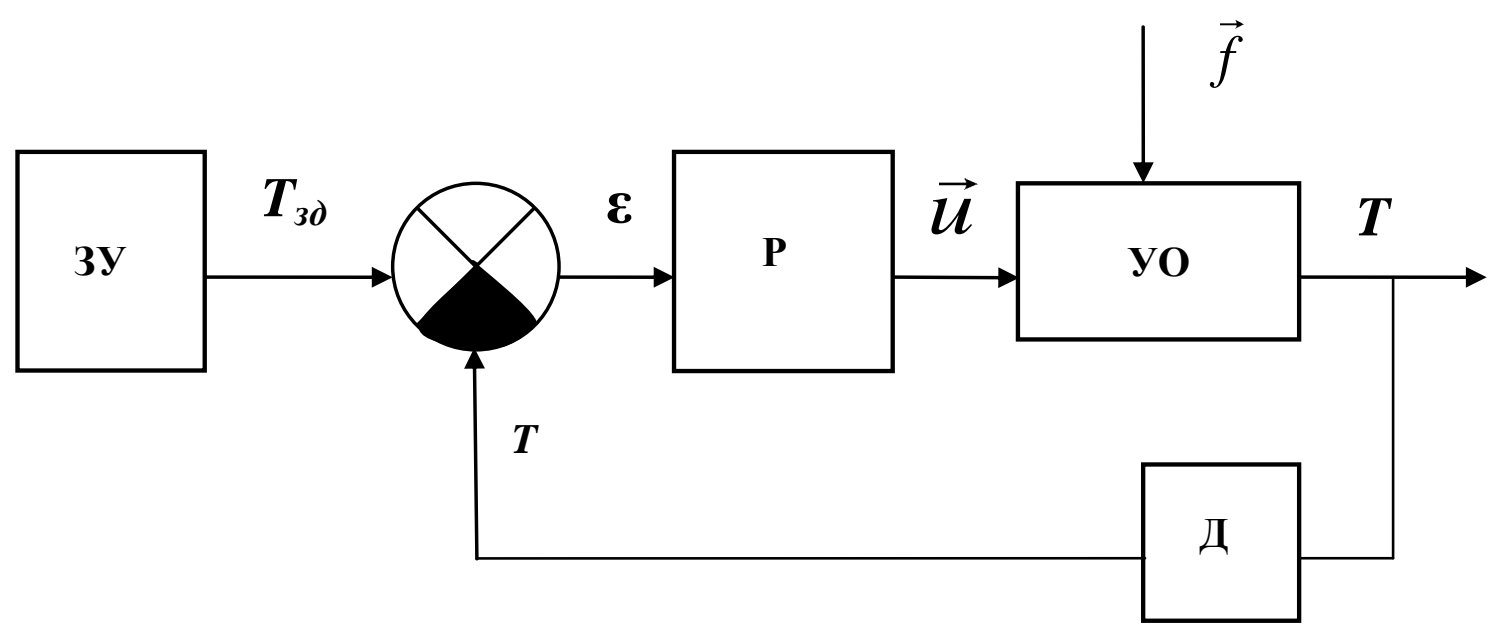

Рис. 1. Структурная схема системы управления объектом, способного к самовозгоранию

На Рис.1 ВОО, допускающий самовозгорание и рассматриваемый в качестве объекта управления, обозначен как УО, Р обозначает регулирующее устройство (регулятор температуры), Д - датчик температуры, $3 \mathbf{У}-$ задающее устройство, передающее сравнивающему устройству информацию о величине температуры $\boldsymbol{T}_{3}$, которую необходимо поддерживать, $\vec{f}$ - вектор возмущений, которые могут иметь разнообразную природу и являются неконтролируемыми, $\boldsymbol{T}$ - измеряемая температура способного к самовозгоранию вещества (выходной параметр), $\boldsymbol{\varepsilon}=\boldsymbol{T}_{\text {зо }}-\boldsymbol{T}$ - разность между задаваемым и измеренным значениями температуры, $\vec{u}-$ вектор управляющих воздействий, которыми могут быть включения и отключения системы охлаждения.

При управлении сложным объектом, взрывобезопасность которого определяется значениями большого числа взаимосвязанных параметров, схема управления с обратной связью, подобная предложенной выше, уже не может быть реализована. Для сложного (пусть даже элементарного в смысле геометрии [11,12], но сложного в физико-химическом смысле) ВОО невозможно задать уровень каждого из параметров состояния этого объекта таким образом, чтобы, с одной стороны объект гарантированно находился в достаточно взрывобезопасном состоянии, а с другой - не нарушался соответствующий технологический процесс. По этой причине, очевидно, отдельные параметры состояния ВОО не следует рассматривать как его выходные параметры. Эти параметры - точнее, изменения этих параметров - скорее следует рассматривать как входы объекта. Структурная схема такой системы управления изображена на Рис.4.

Входными параметрами ВОО в первую очередь могут быть различные физико-химические параметры смеси (гомогенной или гетерогенной), которая является потенциально взрывоопасной. К этим параметрам относятся концентрация горючего (например, концентрация газа в газовой смеси или концентрация пыли в ПВС), давление, температура, влажность и т. п. Изменение любого из этих параметров в той или иной степени изменяет реакционную способность и, как следствие, возможность возгорания смеси. Кроме того, физикохимические параметры смеси определяют размер ячейки пламени и связанную с ним величину гасящего расстояния, длину преддетонационного участка, время развития взрыва и размер детонационной ячейки в случае, когда взрыв является детонацией. Геометрические параметры, определяющие форму объема, в которую заключена взрывоопасная смесь, а также характер поверхности, ограничивающей этот объем, могут рассматриваться в качестве входных параметров лишь в исключительных случаях, так как они практически никогда не могут изменяться в режиме оперативного управления. К числу входов может быть отнесено и инициирующее энерговыделение (его отсутствие или возникновение). К основным выходным параметрам произвольного элементарного [11,12] ВОО нужно отнести возможность возгорания, величину гасящего расстояния, длину преддетонационного участка и время развития взрыва. Таким образом, параметрическую схему элементарного ВОО как УО можно представить в виде, изображенном на Рис. 2. 


\section{1 ПИТАННЯ ТЕОРІЇ, МЕТОДИ ТА АЛГОРИТМИ ЕФЕКТИВНОГО АВТОМАТИЧНОГО} УПРАВЛІННЯ ОБ'ЄКТАМИ ХІМІКО-ТЕХНОЛОГІЧНОГО ТИПУ

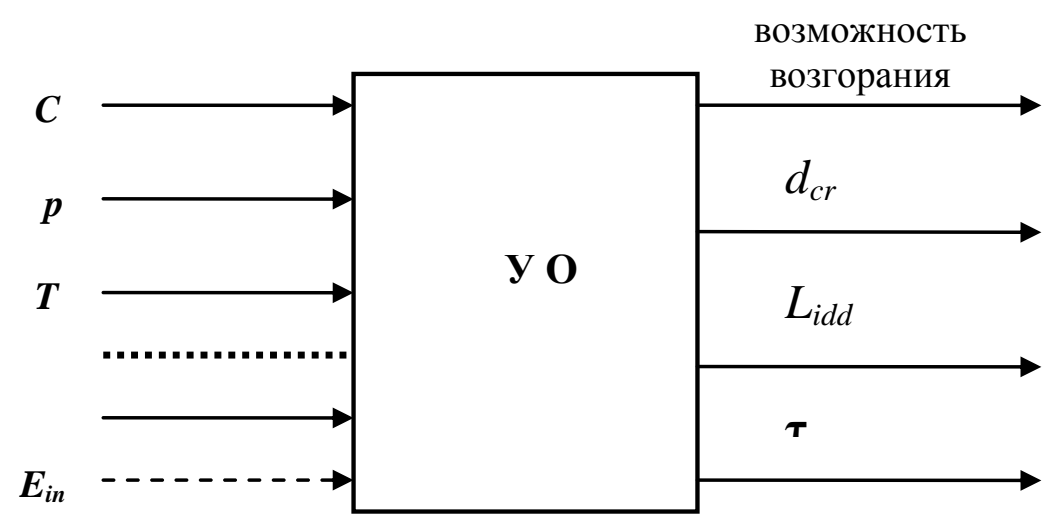

Рис. 2. Параметрическая схема элементарного ВОО как объекта управления

На Рис. 2 элементарный ВОО, рассматриваемый в качестве объекта управления, обозначен как УО; входными параметрами являются концентрация горючего $C$, давление $p$, температура $T$ и т.д. - изменения этих величин можно рассматривать как контролируемые возмущения; входным параметром также является отсутствие или возникновение инициирующего энерговыделения $\left(E_{i n}\right)$, однако это возмущение не является контролируемым (недопущение возникновения инициирующего энерговыделения достигается главным образом методами организационного управления, которые не всегда действенны); выходными параметрами являются возможность возгорания, величина гасящего расстояния $d_{c r}$, длина преддетонационного участка $L_{i d d}$ и время возможного развития взрыва $\tau$.

Особенность выходных параметров элементарного ВОО, изображенного на Рис. 2, состоит в том, что они не измеряются, а вычисляются (четким или нечетким образом) по измеренным параметрам состояния объекта (по входным параметрам). Все эти выходные параметры и не могут быть измерены, так как проявляются лишь при реальном инициировании возгорания и, возможно, последующего взрыва.

Все выходные параметры УО, которым является элементарный ВОО, могут быть сведены [11,12] к единственному показателю - нечеткой оценке взрывоопасности $\tilde{E} \boldsymbol{H}$, изменяющейся в пределах от 0 до 1 и выражающей возможность взрыва. Выходным параметром сложного в смысле геометрии $[11,12]$ ВОО также является нечеткая оценка его взрывоопасности $\tilde{E H}$, полученная в результате дизъюнкции нечетких оценок взрывоопасности каждого из элементарных ВОО, составляющих данный сложный объект. Таким образом, параметрическая схема произвольного ВОО как объекта управления представлена на Рис. 3.

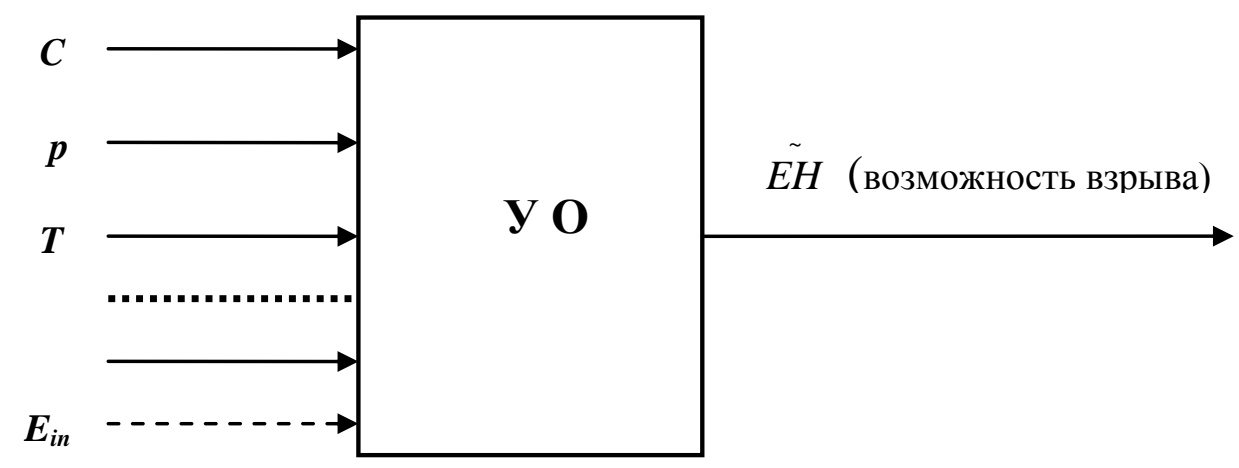

Рис. 3. Параметрическая схема произвольного ВОО как объекта управления

Очевидно, что и управление произвольным ВОО, параметрическая схема которого изображена на Рис. 3, осуществляется не по принципу обратной связи (как на Рис. 1), а по принципу управления по возмущениям (Рис. 4). 


\section{1 ПИТАННЯ ТЕОРІї, МЕТОДИ ТА АЛГОРИТМИ ЕФЕКТИВНОГО АВТОМАТИЧНОГО} УПРАВЛІННЯ ОБ'ЄКТАМИ ХІМІКО-ТЕХНОЛОГІЧНОГО ТИПУ

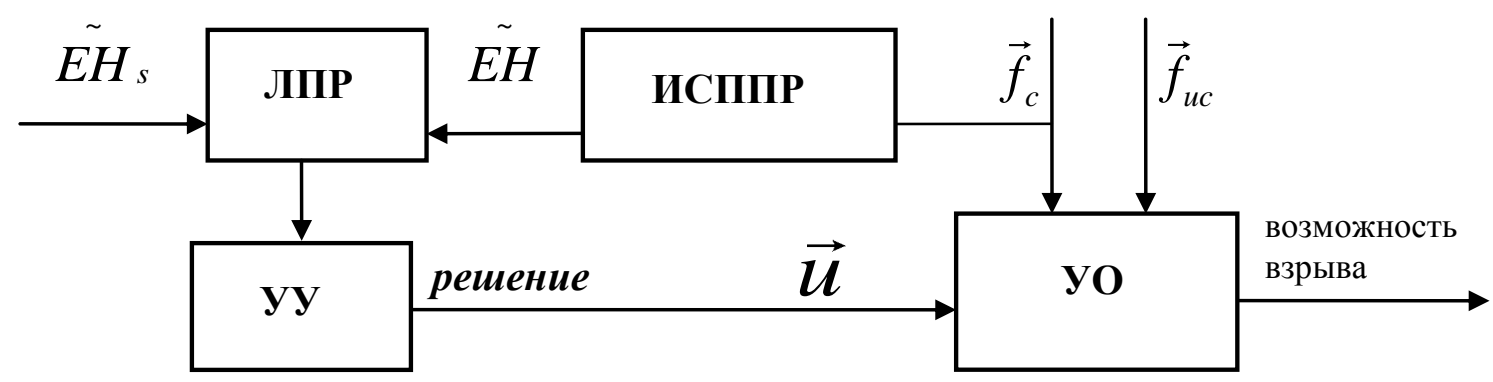

Рис. 4. Структурная схема системы управления произвольным ВОО

При этом интеллектуальная система поддержки принятия решений (ИСППР) определяет уровень взрывоопасности объекта (величину $\tilde{E H}$ ) и передает эту информацию лицу, принимающему решение (ЛПР); в некоторых ситуациях ИСППР сообщает ЛПР также дополнительные сведения: длину преддетонационного участка, предполагаемое время развития взрыва и т.п. (все эти величины рассчитываются как промежуточные при вычислении величины $\tilde{E H})$. ЛПР, сопоставляя величину $\tilde{E H}$ с допустимой и заданной изначально величиной $\tilde{E H}$ (во многих случаях ЛПР непосредственно задает значение этой величины, т.е. определяет допустимый уровень взрывоопасности), принимает решение, которое так или иначе передается управляющему устройству (УУ), которое вырабатывает управляющие воздействия $\vec{u}$. Управляющие воздействия могут быть как технологическими, так и организационными. Технологические управляющие воздействия прежде всего связаны с изменением (мгновенным или постепенным) физико-химических параметров потенциально взрывоопасной среды; к ним относятся ингибирование, включение систем вентиляции, снижение температуры или давления и т.д. Организационные управляющие воздействия, как правило, определяют действия персонала; к таким управляющим воздействиям следует отнести, например, включение различных систем оповещения с последующей полной или частичной эвакуацией объекта, вызов специальных служб (пожарных, медицинских, военных) и т.п. Некоторые управляющие воздействия можно рассматривать как технологические и организационные одновременно (например, проведение влажной уборки запыленного помещения).

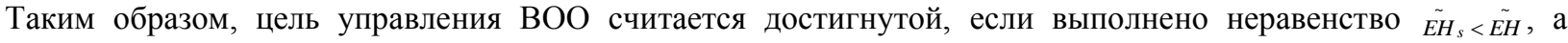
основным принципом управления является принцип (разомкнутого) управления по возмущениям ( $\vec{f}_{c}-$ вектор контролируемых возмущений, $\vec{f}_{u c}$ - вектор неконтролируемых возмущений).

В ряде случаев задача управления ВОО рассматривается как задача логического управления, когда целью управления является изменение общего состояния объекта при возникновении аварийной ситуации, т.е. при возгорании. При такой постановке задачи контролируемым возмущением является как раз возникновение инициирующего энерговыделения, т.е. возгорание, вызванное теми или иными причинами. Выходной параметр $\tilde{E H}$ можно не вычислять, принимая $\tilde{E H}=1$ : даже если это не так и величина $\tilde{E H}$ достаточно мала (т.е. пожар не может перерасти во взрыв) необходимы управляющие воздействия на объект с целью полного гашения пламени и/или локализации пожара. Структурная схема такой системы логического управления ВОО показана на Рис. 5.

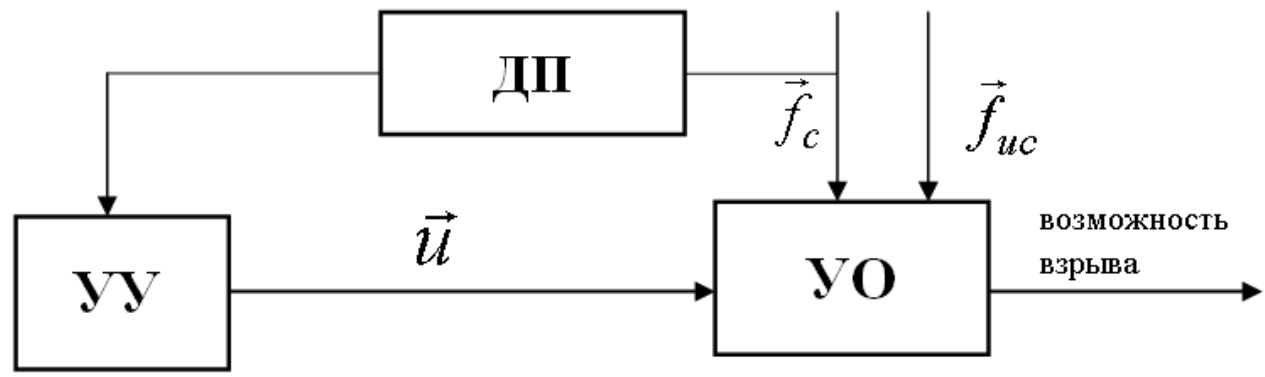

Рис. 5. Структурная схема системы логического управления ВОО 


\section{I ПИТАННЯ ТЕОРІЇ, МЕТОДИ ТА АЛГОРИТМИ ЕФЕКТИВНОГО АВТОМАТИЧНОГО УПРАВЛІННЯ ОБ'ЄКТАМИ ХІМІКО-ТЕХНОЛОГІЧНОГО ТИПУ}

При этом вектор контролируемых возмущений $\vec{f}_{c}$ содержит всего одну компоненту - возникновение возгорания. Детектор пламени (ДП) передает информацию управляющему устройству, которое воздействует на объект, принципиально изменяя его общее состояние (возможны ингибирование, прекращение функционирования объекта или его полная ликвидация, применение заслонок или сброс давления и т.п.). В схеме на Рис. 5 ИСППР по взрывобезопасности отсутствует - она вынесена за рамки системы управления. Однако выбор управляющих воздействий $\vec{u}$ желательно произвести именно при помощи ИСППР, оценив предварительно время возможного развития взрыва $\tau$ : если, например, это время измеряется десятками секунд, необходимо немедленное ингибирование, а если $\tau$ измеряется минутами, то возможны иные, менее дорогостоящие воздействия (естественно, возможные сценарии развития ситуации при возгорании, определяемые текущим - на момент возгорания - состоянием объекта, должны быть заранее «проиграны» ЛПР с помощью ИСППР и запрограммированы в УУ).

Если объект достаточно большой и сложный (в смысле размеров и геометрии) то, руководствуясь данными, полученными при помощи ИСППР о длинах преддетонационных участков и временах возможного развития взрыва, ЛПР может правильно спроектировать расположение детекторов пламени, ингибирующих устройств, огнепреградителей, тамбур-шлюзов, заслонок, мембран и т.п.

Если априори известно, что время развития взрыва достаточно велико, то ИСППР и ЛПР могут быть включены в схему логического управления ВОО, которая приобретает практически такой же вид, как на Рис. 4, но с учетом того, что контролируемым возмущением является возгорание, информацию о наличии которого ИСППР получает от детектора пламени. В данном случае у ЛПР есть время, чтобы, используя данные ИСППР по взрывобезопасности и руководствуясь общей производственной и технологической ситуацией, принять правильное (оптимальное в некотором смысле) решение и реализовать его через УУ.

Перечисленные выше технические устройства, реализующие активные меры по снижению опасности возникновения взрыва или ослаблению его действия, играют роль исполнительных устройств в системе управления, обеспечивающей взрывобезопасность. Эффективное применение таких исполнительных устройств требует оценки их инерционности, т.е. оценки времени, необходимого для реализации действия соответствующего технического устройства. Точнее, необходимо произвести оценку инерционности УО, которым является ВОО, по каналу управления.

В Таблице 1 приведены характерные времена реализации различных управляющих воздействий на ПВОО.

Таблица 1 - Инерционность различных видов управляющих воздействий на ВОО

\begin{tabular}{|c|c|}
\hline Управляющее воздействие & $\begin{array}{c}\text { Время } T_{\text {и }} \text { реализации управляющего воздействия (в } \\
\text { секундах) }\end{array}$ \\
\hline $\begin{array}{c}\text { Аварийная остановка процесса } \\
\text { (общее обесточивание) }\end{array}$ & $0,1 \div 2$ \\
\hline Введение ингибитора или флегматизатора & $0,5 \div 2$ \\
\hline $\begin{array}{c}\text { Сброс давления через принудительно } \\
\text { открываемые отверстия }\end{array}$ & $1 \div 3$ \\
\hline $\begin{array}{c}\text { Блокирование места взрыва отсечными } \\
\text { устройствами }\end{array}$ & $3 \div 10$ \\
\hline $\begin{array}{c}\text { Блокирование места взрыва инертными } \\
\text { зонами }\end{array}$ & $1 \div 5$ \\
\hline
\end{tabular}

Автоматическая аварийная остановка процесса и введение ингибитора (или флегматизатора) могут применяться как до возможного возгорания - т.е. в случае, когда возможность взрыва слишком велика - так и после возникновения очага горения. Аварийная остановка процесса, как правило, не дает гарантии взрывобезопасности и применяется в сочетании с другими управляющими воздействиями.

Автоматическое блокирование места взрыва или возгорания, как правило, применяется уже после возникновения возгорания, что препятствует распространению как пожара, так и взрыва. При этом блокирование места взрыва инертными зонами не может воспрепятствовать распространению ударной волны, но в значительной степени локализует взрыв, а также препятствует переходу дефлаграционного взрыва в детонационный. Не исключается автоматическое блокирование места возможного взрыва, если возможность взрыва слишком велика.

Автоматический сброс давления через принудительно открываемые отверстия применяется только на ранней стадии развития взрыва, т.е. уже после возгорания. 


\section{1 ПИТАННЯ ТЕОРІЇ, МЕТОДИ ТА АЛГОРИТМИ ЕФЕКТИВНОГО АВТОМАТИЧНОГО УПРАВЛІННЯ ОБ'ЄКТАМИ ХІМІКО-ТЕХНОЛОГІЧНОГО ТИПУ}

Если пренебречь временем передачи сигналов, то инерционность ПВОО (как УО) по каналу управления в САУ определяется (см. Рис. 6):

1) инерционностью датчиков;

2) инерционностью управляющих воздействий;

3) временем, которое затрачивает вычислительное устройство на обработку сигналов датчиков.

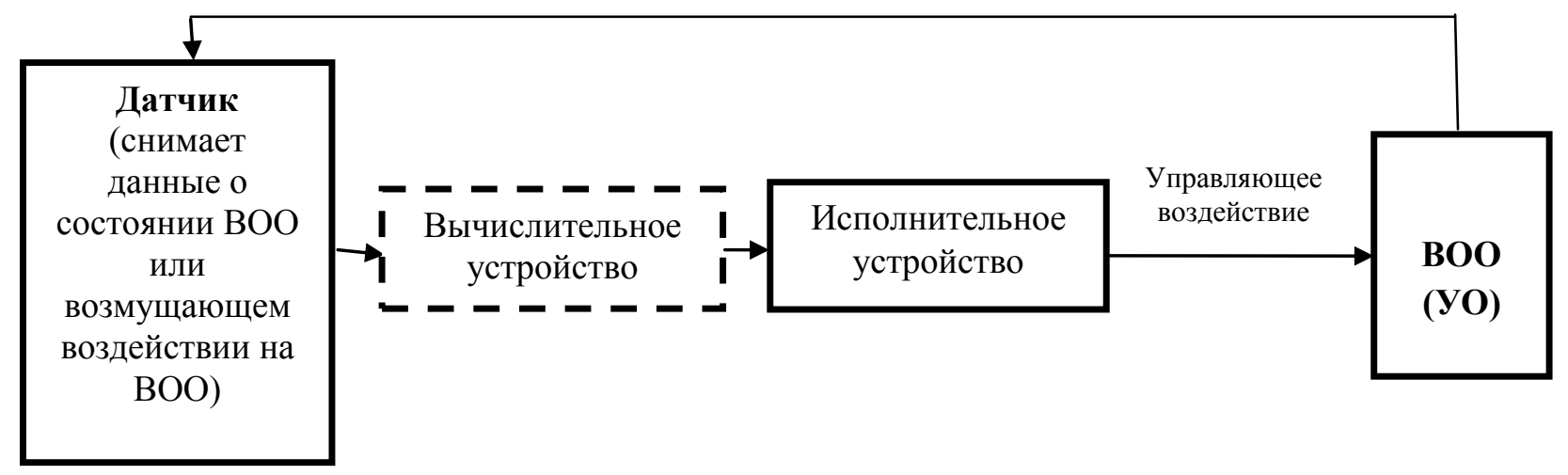

Рис. 6. Схема прохождения сигнала в САУ ПВОО

Детекторы пламени и датчики давления имеют малую инерционность ( 0,1 с, не более). Время работы вычислительного устройства - если оно предусмотрено в системе автоматического управления (САУ) в виде отдельной компоненты - составляет миллисекунды, так как определяется временем вычисления значений одной или нескольких простейших логических функций. Так как инерционность датчиков и вычислительных устройств мала по сравнению с инерционностью исполнительных устройств в САУ ВОО, то инерционность УО по каналу управления фактически определяется инерционностью соответствующего исполнительного механизма (управляющего воздействия).

Инерционность ПВОО по каналу управления в АСУ с участием оператора (см. Рис.7) определяется - в первую очередь - временем принятия решения самим оператором.

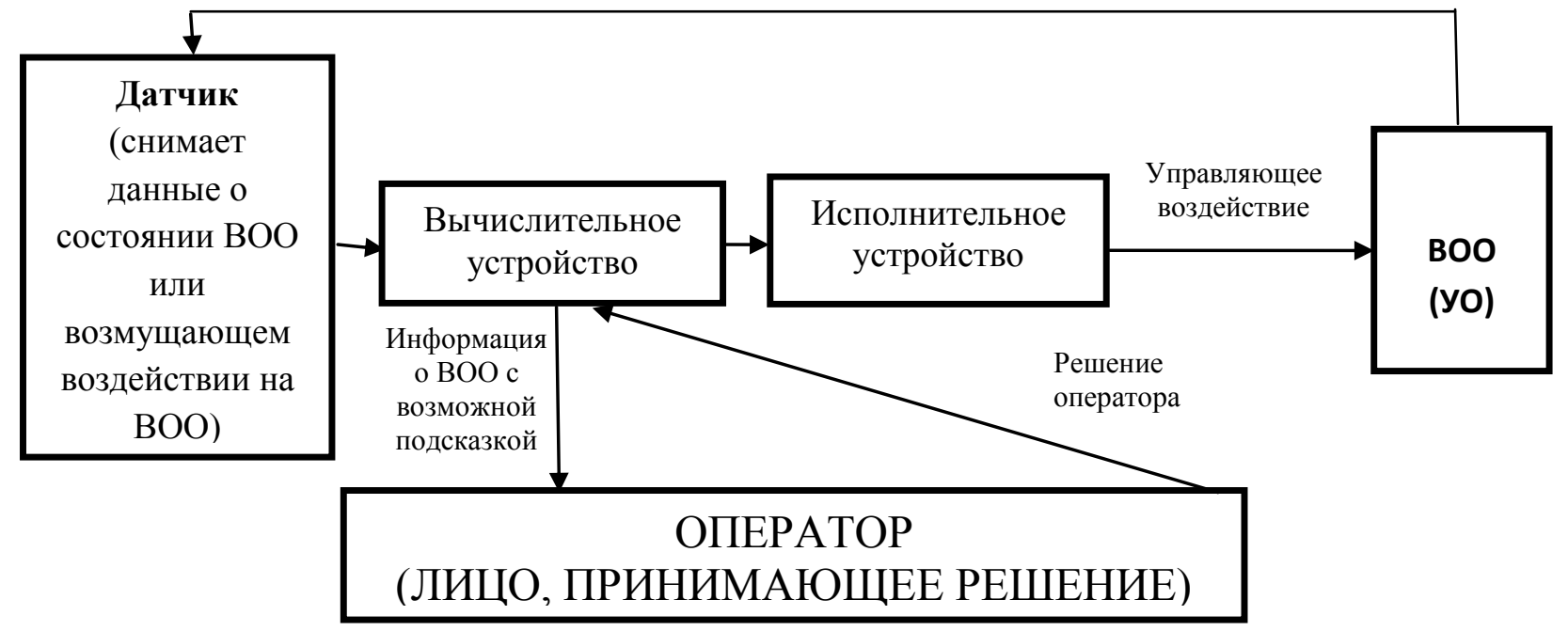

Рис. 7. Схема прохождения сигнала в АСУ ПВОО

Оператор, получив (обработанную) информацию о состоянии ВОО или о возмущающем воздействии на ВОО (наиболее мощным возмущающим воздействием является возникновение очага пламени), принимает решение, которое, через вычислительное устройство, передается (тому или иному - если есть альтернатива) исполнительному устройству для оказания управляющего воздействия на ВОО. Можно считать, что время 


\section{I ПИТАННЯ ТЕОРІЇ, МЕТОДИ ТА АЛГОРИТМИ ЕФЕКТИВНОГО АВТОМАТИЧНОГО} УПРАВЛІННЯ ОБ'ЄКТАМИ ХІМІКО-ТЕХНОЛОГІЧНОГО ТИПУ

принятия решения даже подготовленным и внимательным оператором составит не менее 10 с. Поэтому желательно, чтобы вычислительное устройство АСУ реализовало основную функцию ИСППР, т.е. генерировало соответствующие подсказки оператору. Эти подсказки должны в обязательном порядке содержать информацию:

1) об уровне взрывоопасности ВОО и/или отдельных его компонент;

2) о времени (возможного) перехода горения во взрыв.

Подсказка от вычислительного устройства дает возможность оператору оценить имеющееся в его распоряжении время для принятия решения, а также принять корректное решение максимально быстро.

В случае возникновения очага пламени АСУ может автоматически реализовать управляющее воздействие на ПВОО, если оператор опоздает с принятием решения.

Очевидно, что инерционность ВОО по каналу управления для АСУ с участием оператора достаточно велика по сравнению с инерционностью ВОО для САУ. Единственный способ снижения инерционности ВОО в случае АСУ состоит в уменьшении времени, затрачиваемого на принятие решения оператором.

Вопрос о возможности функционирования АСУ ВОО с участием оператора и о применимости тех или иных управляющих воздействий на ПВОО тесно связан с оценкой времени перехода горения во взрыв при возгорании, или, в терминах теории автоматического управления, с оценкой инерционности ВОО по каналу возмущений.

\section{Выводы}

1. Инерционность ВОО по каналу управления в САУ невелика.

2. Инерционность ВОО по каналу управления в АСУ с участием оператора существенно выше, чем в САУ, но может быть снижена за счет применения ИСППР по взрывобезопасности.

3. Обеспечивающая подсистема АСУ ВОО должна включать в себя математическое обеспечение, позволяющее адекватно оценивать уровень взрывоопасности объекта и время возможного перехода горения во взрыв (инерционность объекта по каналу возмущений).

\section{Литература}

1. Васильев Я.Я. Взрывобезопасность на предприятиях по хранению и переработке зерна / Я.Я. Васильев, Л.И. Семенов - М.: Колос.- 1983. - 224с.

2. Взрывные явления. Оценка и последствия: В 2-х кн. Кн.1 /У. Бейкер, П. Кокс, П. Уэстайн и др. - М: Мир, 1986. - 319 с.

3. Взрывные явления. Оценка и последствия: В 2-х кн. Кн.2 /У. Бейкер, П. Кокс, П. Уэстайн и др. - М: Мир, 1986. - 384 с.

4. Нетлетон М. Детонация в газах. - М: Мир, 1989. - 280 с.

5. Маршалл В. Основные опасности химических производств. - М.:Мир, 1989. - 672 с.

6. Семенов Л.И. Взрывобезопасность элеваторов, мукомольных и комбикормовых заводов /Л.И. Семенов, Л.А. Теслер - М.: Агропромиздат.- 1991. - 367 с.

7. Nettleton, M. A. Gaseous detonations: their nature and control. - [S.I.] : Springer, 2013. -255 p.

8. Kauffman C.W. The DeBruce Grain Elevator Explosion // Seventh International Symposium on Hazards, Prevention and Mitigation of Industrial Explosions: Thirteeenth International Colloquim on Dust Explosions \& Eigth Colloquim on Gas, Vapor, Liquid, and Hybrid Explosions. St. Petersburg, Russia. July 7-11, 2008. - St. Petersburg, 2008. - Vol.3. - P.3-26.

9. Volkov V.E. Decision Support Systems on Hazards of Industrial Explosions //Seventh International Symposium on Hazards, Prevention and Mitigation of Industrial Explosions: Thirteeenth International Colloquium on Dust Explosions \& Eighth Colloquim on Gas, Vapor, Liquid, and Hybrid Explosions. St. Petersburg, Russia. July 7-11, 2008. - St. Petersburg, 2008. - Vol.3. - P.343-347.

10. Проблемы коэволюции и социотехническое управление: научно-учебное пособие /Б.В. Егоров, И.Н. Буценко, А.А.Шевченко, А.В. Коваленко, В.Э. Волков, И.И. Яровой, Г.В. Ангелов - Одесса: КП ОГТ, 2010. - 624c.

11. Волков В.Э. Информационная модель потенциально взрывоопасного объекта. Часть 1 // Автоматизация технологических и бизнес-процессов, 2012. - №№9,10 март-июнь 2012. - С. 3-11.

12. Волков В.Э. Информационная модель потенциально взрывоопасного объекта. Часть 2 // Автоматизация технологических и бизнес-процессов, 2012. - №№11,12 сентябрь-декабрь 2012. - С. 3-9. 